\title{
Public priorities and consumer preferences for selected attributes of automated vehicles
}

\author{
Paulina Lustgarten ${ }^{1} \cdot$ Scott Le Vine ${ }^{1,2,3}{ }_{(\mathbb{C}}$
}

Received: 7 May 2017/Revised: 11 October 2017/Accepted: 24 October 2017 / Published online: 16 November 2017

(C) The Author(s) 2017. This article is an open access publication

\begin{abstract}
Public opinion and consumer preferences are among the various constraints on the rollout of automated cars, as they will affect the decision-making of both automotive industry actors and public-sector regulators. This study contributes to the growing body of the literature regarding this issue, through a moderate-scale survey $(n=370)$ that incorporated both prioritization/attitudinal questions (regarding public opinion) and a stated-preference module (to identify consumer preferences). The survey protocol includes a stated-preference approach to investigate consumers' preferences for the possibility of very high rates of speed in automated cars on long-distance journeys. We found separately identifiable effects for average travel speeds (manifested as journey duration) and maximum travel speed in the stated-preference scenarios. In the 'prioritization' component of the survey, respondents ranked having the 'highest possible level of safety' as the single most important benefit that they would like automated cars to deliver, ahead of benefits such as being able to performing activities while traveling or having traffic congestion reduced. This result has consequences for the car-following distances that are programmed into the control algorithms of automated cars. Documenting this
\end{abstract}

Scott Le Vine

levines@newpaltz.edu

1 Department of Geography, State University of New York (SUNY) at New Paltz, Hawk Drive, New Paltz, NY 12561, USA

2 School of Transportation and Logistics, Southwest Jiaotong University, 111 N. 1st Section, 2nd Ring Road, Chengdu 610031, People's Republic of China

3 Department of Civil and Environmental Engineering, Imperial College London, Exhibition Road, South Kensington SW7 2AZ, UK finding is important, as decisions must be made in the near future by driving-algorithm designers, public-sector regulators, and ultimately the judiciary regarding the guidelines for acceptable automated driving-behavior instructions.

Keywords Automated car - Stated-preference $\cdot$ Logistic regression

\section{Introduction}

The consequences of vehicle automation are potentially far reaching; however, the body of the literature regarding consumer preferences and public opinion is now in its formative stages (Table 1 summarizes these recent studies [1-6]) and relatively little is known with reliability.

The objective of this study is to identify novel aspects of consumer preferences and public opinion regarding highly automated cars (levels 2 through 4 under the NHTSA taxonomy [7]). For instance, we investigate consumers' relative prioritization of various prospective benefits of automated cars and their preferences for travel at higher rates of free-flow speed than at present; neither of these issues are addressed in the prior literature. To do this, we designed a survey protocol that included both attitudinal questions and a stated-preference component. The survey was administered to a moderate-sized sample $(n=370)$, which was generated according to a sampling plan based on age/gender quotas (the sampling strategy is described in detail in Sect. 3). Therefore, the results can be interpreted as being nationally representative along these dimensions; however, larger sample $(n>>1000)$ follow-on surveying will be required to have greater confidence in the findings.

The remainder of this paper is organized as follows. Section 2 describes the survey protocol that we designed 
Table 1 Summary of earlier studies of attitudes and consumer preferences toward automated cars

\begin{tabular}{|c|c|c|c|}
\hline Citation & Coverage & Data & Selected findings \\
\hline Schoettle and Sivak [1] & $\begin{array}{l}\text { US }(n=501) \text {, as well as } 5 \text { other } \\
\text { countries (Australia, China, } \\
\text { India, Japan, UK) }\end{array}$ & $\begin{array}{l}\text { Attitudinal and opinion questions; } \\
\text { sample recruited from online } \\
\text { panel of Survey Monkey; data } \\
\text { collected in } 2014\end{array}$ & $\begin{array}{l}\text { Majority of respondents expressed high } \\
\text { levels of concern about riding in } \\
\text { automated cars, safety issues related to } \\
\text { equipment or system failure, and } \\
\text { automated cars not performing as well } \\
\text { as human drivers }\end{array}$ \\
\hline Piao et al. [2] & $\begin{array}{l}n=148 \text { respondents near a } \\
\text { demonstrator route of an } \\
\text { automated bus in La Rochelle, } \\
\text { France. } n=500 \text { respondents } \\
\text { resident across La Rochelle }\end{array}$ & $\begin{array}{l}\text { Attitudinal and opinion questions; } \\
\text { CASI }(n=148) \text { and CATI } \\
(n=500) ; \text { data collected in } \\
\text { early } 2015\end{array}$ & $\begin{array}{l}\text { Among a listing of potential benefits of } \\
\text { automated cars, the items sought by the } \\
\text { largest share of respondents were } \\
\text { 'Increase mobility for the elderly, } \\
\text { disabled and others' (58\% answered } \\
\text { 'very attractive') and 'Reduce fuel } \\
\text { consumptions and emissions' (56\% } \\
\text { answered 'very attractive'). The least- } \\
\text { sought benefits were: 'No need to } \\
\text { spend time and cost on learning how to } \\
\text { drive' ( } 19 \% \text { answered very attractive') } \\
\text { and 'Allow 'drivers' to do other things } \\
\text { while 'driving'" ( } 20 \% \text { answered 'very } \\
\text { attractive') }\end{array}$ \\
\hline J. D Power [3] & $\begin{array}{l}n=7947 \text { owners of } 2012 \text { or newer } \\
\text { model year cars }\end{array}$ & $\begin{array}{l}\text { Attitudinal and opinion questions; } \\
\text { data collected February/March } \\
2016\end{array}$ & $\begin{array}{l}\text { Trust in automated car technologies } \\
\text { negatively linked with age. Likewise, } \\
\text { greater interest in automated mobility } \\
\text { on demand systems among young } \\
\text { adults than older groups }\end{array}$ \\
\hline Zmud et al. [4] & $\begin{array}{l}\text { Residents of Austin, Texas } \\
\quad(n=556)\end{array}$ & $\begin{array}{l}\text { Attitudinal and opinion questions; } \\
\text { web-based CASI }\end{array}$ & $\begin{array}{l}\text { Half of respondents indicated they are } \\
\text { unlikely to use an automated car for } \\
\text { everyday use. Demographic indicators } \\
\text { were weaker predictors of intent to use } \\
\text { than psychosocial indicators such as } \\
\text { technology adoption, privacy concerns, } \\
\text { and perceptions of safety }\end{array}$ \\
\hline Weinstein [5] & $\begin{array}{l}\text { Residents of Seattle, Washington } \\
\text { (sample size not specified) }\end{array}$ & $\begin{array}{l}\text { Stated-preference survey; context } \\
\text { is whether future car purchases } \\
\text { will be 'manual' or automated } \\
\text { car }\end{array}$ & $\begin{array}{l}\text { Results of modeling stated-preference } \\
\text { data not published; descriptive findings } \\
\text { include females, young age groups, and } \\
\text { smartphone owners expressing greater } \\
\text { interest in using AVs }\end{array}$ \\
\hline Kreuger et al. [6] & $\begin{array}{l}\text { Urban residents of Australia } \\
\quad(n=465)\end{array}$ & $\begin{array}{l}\text { Stated-preference survey; context } \\
\text { is mode choice for a reference } \\
\text { journey (pivoted off } \\
\text { respondent's self-report of a } \\
\text { recent trip they had made), } \\
\text { where shared automated cars are } \\
\text { introduced }\end{array}$ & $\begin{array}{l}\text { Results of modeling stated-preference } \\
\text { data demonstrate the salience of } \\
\text { waiting time (between trip-request and } \\
\text { shared automated car's arrival) for } \\
\text { prospective users. Younger adults more } \\
\text { likely to use the shared service, and } \\
\text { service found to be more attractive for } \\
\text { work-related trips than other journey } \\
\text { types }\end{array}$ \\
\hline
\end{tabular}

and executed in this study. Section 3 then presents and discusses the empirical results, and Sect. 4 summarizes and concludes this paper.

\section{Overview of survey protocol}

The survey protocol comprised three distinct modules, which respondents completed in the following sequence:
- Demographic information.

- Hypothetical stated-preference scenarios.

- Attitudinal questions.

The survey protocol was reviewed and approved by the SUNY New Paltz Human Research Ethics Board and pilottested with college staff as respondents prior to the main fieldwork. The survey fieldwork was performed via webbased computer-aided self-administration (CASI). The fieldwork was undertaken by the market-research firm Qualtrics, which maintains market-research panels to 
which researchers can purchase access. The present survey had a straightforward sampling plan (a nationally representative sample in terms of age and gender), which served to control costs; a more-complex quota plan (e.g., introducing a requirement for a minimum number of respondents that do not hold a driving license) would have had corresponding impacts on resource requirements for this study. Respondents received incentives in the form of '...points [that] can be pooled and later redeemed in the form of gift cards, skymiles, credit for online games, etc' ${ }^{1}$ The value of the incentives are variable (depending in part on whether a particular respondent is in a difficult-to-reach segment of the sample quota) and were approximately equivalent to $\$ 1 /$ respondent for completing this survey.

Only complete responses (i.e., no partially completed surveys) were provided in the final dataset. No surveys completed in less than 4 min were included in the final dataset. The average time to complete the survey was $14 \mathrm{~min}$ and $43 \mathrm{~s}$.

Data were collected in four batches of approximately equal sizes:
1. April 25, 2016
2. May 9, 2016.
3. May 17, 2016.
4. May 19, 2016.

The survey questionnaire was identical across the four batches, with the exception of the numerical values in the stated-preference module. The logic for varying the numerical values in the stated-preference module is to increase the variability in the dataset, which increases the robustness of the regression parameters and minimizes the opportunity for collecting stated-preference data that do not provide useful information in model estimation (see Sect. 3).

For the purposes of communicating with respondents within the survey, we elected to consistently use the term 'driverless car' rather than 'automated car.'

\subsection{Design of stated-preference module}

In the stated-preference module, respondents were presented with the task of deciding how to travel to 'see relatives that live in another part of the country' and were presented the following options:

- Drive a 'normal' car or take a bus (see two paragraphs below).

- A 'semi-driverless' car. ${ }^{2}$

- A 'completely driverless' car.

\footnotetext{
${ }^{1}$ Personal communication from Qualtrics' S.J. Campbell, 4/14/2016.

2 The text describing the driverless cars is as follows:
}

- Take a commercial air flight.

'Visiting relatives' was chosen as the hypothetical activity, because in comparison with other activities that were considered by the research team (e.g., business travel, tourism) it was felt that visiting relatives would likely be a type of long-distance travel that is familiar to a larger share of respondents.

The stated-preference module consisted of 10 replications for each respondent. During each replication, the cost and duration and maximum speed of each of the options in the listing above were varied according to a pre-defined D-efficient design prepared by the research team [8].

The questionnaire branched on the basis of whether or not the respondent holds a driver's license. In the statedpreference module, licensed respondents were presented with the option to drive a 'normal' (i.e., not automated) car if they wish, whereas unlicensed respondents were instead provided the option to take an inter-city bus. Also, respondents who do not hold a driving license were only presented with the option of using a 'fully automated' car (i.e., NHTSA level 4), whereas respondents holding a driving license were also presented in specific scenarios with the option of using a 'partly automated' car (NHTSA level 2/3). The questionnaires were otherwise identical, with the exception of a question about how fast drivers drive on Interstate Highways (which was not asked of unlicensed respondents and is not analyzed in this paper).

\section{Results}

Table 2 presents descriptive results of the sample regarding socio-demographics and spatial characteristics of their residence. Pluralities reported being married $(42 \%)$ and living in a suburban location (46\%); $70 \%$ reported household income of under $\$ 75,000 /$ year, approximately two-

Footnote 2 continued

Carmakers are now experimenting with driverless cars, which use sensors and computers to 'drive' themselves. It works a bit like an advanced form of Cruise Control, but you tell a driverless car the destination address of your journey and it is able to brake by itself, change lanes, and make turns to get you there. In the different scenarios, you will see two types of "driverless cars":

1. A "semi-driverless" car can drive itself for nearly all of the journey (you just need to enter the destination address). However, you must keep your hands on the steering wheel and be ready to take control at any time in case something goes wrong to avoid accidents.

2. A "completely-driverless" car will drive itself for the entire journey, after you tell it your destination. You are free to do whatever you wish as you travel with no need to ever keep your hands on the wheel, as the car avoids accidents on its own. 
thirds $(68 \%)$ of respondents reported living without children in their household, and $90 \%$ reported having a full (i.e., excluding learner's permits) driving license.

Table 2 Descriptive statistics of the sample

\begin{tabular}{|c|}
\hline Statistic/value \\
\hline Female/Male: $50 \% / 50 \%$ \\
\hline Age \\
\hline $15-17: 1 \%$ \\
\hline 18-20: $2 \%$ \\
\hline 21-29: $16 \%$ \\
\hline 30-39: $19 \%$ \\
\hline 40-49: $16 \%$ \\
\hline 50-59: $19 \%$ \\
\hline 60-69: $16 \%$ \\
\hline $70+: 11 \%$ \\
\hline Relationship status \\
\hline Married: $42 \%$ \\
\hline Widowed: $5 \%$ \\
\hline Divorced: $16 \%$ \\
\hline Separated: $1 \%$ \\
\hline Domestic partnership: $3 \%$ \\
\hline Single, but living with significant other: $8 \%$ \\
\hline Single, never married: $25 \%$ \\
\hline Area of residence \\
\hline Rural: $16 \%$ \\
\hline Small town: $15 \%$ \\
\hline Suburban: $46 \%$ \\
\hline Urban: $22 \%$ \\
\hline Unsure: $1 \%$ \\
\hline Approximate household income (last year) \\
\hline Up to $\$ 25 \mathrm{~K}: 24 \%$ \\
\hline$\$ 25-\$ 50 \mathrm{~K}: 26 \%$ \\
\hline$\$ 50-\$ 75 \mathrm{~K}: 20 \%$ \\
\hline$\$ 75-\$ 100 \mathrm{~K}: 16 \%$ \\
\hline$\$ 100-\$ 200 \mathrm{~K}: 10 \%$ \\
\hline$\$ 200 \mathrm{~K}+: 1 \%$ \\
\hline Unsure: $1 \%$ \\
\hline Prefer not to answer: $4 \%$ \\
\hline Presence of children (under age 18) in household \\
\hline Yes: $31 \%$ \\
\hline No: $68 \%$ \\
\hline Prefer not to answer: $1 \%$ \\
\hline Driver's license status \\
\hline Yes: $90 \%$ \\
\hline No: $10 \%$ \\
\hline
\end{tabular}

\subsection{Prioritization and attitudinal results}

After the stated-preference module (see Sect. 3.2), the survey concluded with a set of attitudinal questions. The first three of these questions asked about speed selection when driving 'manually' (not discussed further in this paper), preferences for programming instructions of autonomous cars, and prioritization of their benefits. In order to minimize primary effects for the questions consisting of agreement with statements or prioritization, the order in which these statements were presented was randomized (i.e., different for different respondents). In Tables 3 and 4, color coding is used for ease of interpretation (darkest green for the largest percentages and darkest red for the smallest percentages, excluding 'Unsure' responses).

\subsubsection{Prioritization of automated cars' programming instructions}

Respondents were presented the following paragraph of text which describes the trade-off between safety and congestion. Respondents then indicated which of the following responses best describes their view:

Driverless cars will need to be programmed with instructions of how to follow behind other cars. Following closely can reduce the severity of traffic congestion, but this could increase the risk of rearend crashes. Which of these statements best describes your view of how driverless cars should be programmed:

- Driverless cars should be programmed to follow closely behind the car ahead of it in traffic, in order to reduce traffic congestion, even if this increases the possibility of rear-ending the car ahead: $\mathbf{9 \%}$.

- The person riding in a driverless car should have the choice of whether to leave a large distance behind the car ahead of it, if they wish to reduce the possibility of rear-ending the car ahead, even if this makes traffic congestion worse: $\mathbf{4 8 \%}$.

- Driverless cars should be programmed to leave a large distance behind the car ahead of it, in order to reduce the possibility of rear-ending the car ahead, even if this makes traffic congestion worse: $\mathbf{4 2 \%}$.

It can be seen that only a small minority of respondents (9\%) indicated that congestion reduction should be prioritized over safety. The large majority felt that either the choice of how to make this trade-off should rest with the occupant of an automated car (48\%) or that automated cars should be programmed to prioritize safety over congestion reduction. 
Table 3 Preferences for automated cars' programming instructions

\begin{tabular}{|l|c|c|c|c|c|}
\hline $\begin{array}{l}\text { Driverless cars may open up new } \\
\text { possibilities. Please rank how important } \\
\text { each of the following items would be to you, } \\
\text { with 1 meaning "most important" and 5 } \\
\text { meaning "least important": }\end{array}$ & $\begin{array}{c}\text { Most } \\
\text { important (\%) }\end{array}$ & $2(\%)$ & $3(\%)$ & $4(\%)$ & $\begin{array}{c}\text { Least } \\
\text { important (\%) }\end{array}$ \\
\hline $\begin{array}{l}\text { Being able to read, sleep, send text messages or } \\
\text { do other activities inside the car besides driving, } \\
\text { while the car does the driving }\end{array}$ & 9 & 19 & 23 & 25 & 23 \\
\hline $\begin{array}{l}\text { Being able to send a driverless car to pick up or } \\
\text { drop off packages, groceries, or children, } \\
\text { without a human driver inside the vehicle }\end{array}$ & 13 & 17 & 16 & 22 & 32 \\
\hline $\begin{array}{l}\text { Having the highest possible level of safety in a } \\
\text { driverless car }\end{array}$ & 51 & 12 & 12 & 10 & 15 \\
\hline $\begin{array}{l}\text { Having traffic congestion reduced, so that traffic } \\
\text { moves more smoothly even when there are } \\
\text { many cars on the road }\end{array}$ & 15 & 29 & 25 & 21 & 11 \\
\hline $\begin{array}{l}\text { When there are few other cars on the road, } \\
\text { being able to travel much faster (higher speed) } \\
\text { than drivers are allowed to drive today }\end{array}$ & 12 & 23 & 24 & 22 & 19 \\
\hline
\end{tabular}

\subsubsection{Prioritization of benefits from automated cars}

Table 3 shows results from a question in which respondents were asked to prioritize among five prospective benefits of automated cars:

- Being able to read, sleep, send text messages, or do other activities inside the car besides driving, while the car does the driving.

- Being able to send a driverless car to pick up or drop off packages, groceries, or children, without a human driver inside the vehicle.

- Having the highest possible level of safety in a driverless car.

- Having traffic congestion reduced, so that traffic moves more smoothly even when there are many cars on the road.

- When there are few other cars on the road, being able to travel much faster (higher speed) than drivers are allowed to drive today.

A simple majority of respondents (51\%) chose the 'highest possible level of safety' as their top priority, more than three times the proportion that selected any other item as their top priority. The most frequently cited second priority was congestion reduction, and at the opposite end of the scale, the most frequently cited item as respondents' lowest priority is the ability to send an unoccupied driverless car to perform errands. The item cited least frequently as the top priority was being able to do other activities while inside a car (9\%); this is consistent with findings from Piao et al. [2] (see Table 2).

\subsubsection{Attitudinal results}

Table 4 shows results from a set of questions designed by the research team to investigate attitudes thought to affect one's views regarding automated cars. In the interests of space, we comment on a subset of the results presented in Table 4.

Respondents indicated strong preferences for preferring to travel by car than public transportation, yet a majority indicated that they agreed that they care about environmental issues. Fully $65 \%$ of respondents reported enjoying driving.

Majorities expressed willingness to pay more (51\%) and accept slower travel (54\%) in exchange for greater comfort while traveling. Nearly two out of five respondents (39\%), however, indicated that speed is the most important factor in how they travel. 
Table 4 Resposes to attitudinal questions

\begin{tabular}{|c|c|c|c|c|c|c|}
\hline & $\begin{array}{l}\text { Strongly } \\
\text { agree } \\
(\%)\end{array}$ & $\begin{array}{l}\text { Agree } \\
(\%)\end{array}$ & $\begin{array}{c}\text { Neither } \\
\text { agree } \\
\text { nor } \\
\text { disagree } \\
(\%)\end{array}$ & $\begin{array}{l}\text { Disagree } \\
(\%)\end{array}$ & $\begin{array}{c}\text { Strongly } \\
\text { disagree } \\
(\%)\end{array}$ & $\begin{array}{l}\text { Unsure } \\
(\%)\end{array}$ \\
\hline I enjoy driving & 27 & 38 & 20 & 8 & 7 & 1 \\
\hline $\begin{array}{l}\text { If I had the choice, I would rather be } \\
\text { driven around in a car than be a driver }\end{array}$ & 23 & 31 & 16 & 16 & 13 & 1 \\
\hline $\begin{array}{l}\text { I am confident when using new } \\
\text { technologies }\end{array}$ & 19 & 35 & 24 & 15 & 6 & 1 \\
\hline I prefer cars to public transportation & 48 & 32 & 12 & 4 & 3 & 1 \\
\hline $\begin{array}{l}\text { I trust new technologies to be safe and } \\
\text { reliable }\end{array}$ & 16 & 28 & 29 & 13 & 10 & 4 \\
\hline $\begin{array}{l}\text { If I needed to travel with children, I } \\
\text { would rather drive than fly regardless of } \\
\text { how long it would take }\end{array}$ & 19 & 32 & 20 & 13 & 9 & 7 \\
\hline $\begin{array}{l}\text { When traveling with others I would } \\
\text { rather drive than fly regardless of } \\
\text { distance }\end{array}$ & 24 & 23 & 24 & 18 & 9 & 2 \\
\hline $\begin{array}{l}\text { When traveling with children it is easier } \\
\text { to use private transportation than } \\
\text { public }\end{array}$ & 34 & 31 & 16 & 8 & 6 & 5 \\
\hline $\begin{array}{l}\text { During this 'game', while choosing how } \\
\text { to get to my relative's home, I assumed I } \\
\text { was traveling alone }\end{array}$ & 24 & 25 & 21 & 18 & 7 & 4 \\
\hline I care about environmental issues & 26 & 40 & 21 & 7 & 6 & 0 \\
\hline $\begin{array}{l}\text { Environmental factors play a role in my } \\
\text { travel choices }\end{array}$ & 14 & 25 & 28 & 17 & 16 & 0 \\
\hline I tend to carpool when it is possible & 7 & 17 & 24 & 17 & 31 & 4 \\
\hline $\begin{array}{l}\text { If possible, I would rather walk or ride a } \\
\text { bike to a local destination than drive or } \\
\text { take public transportation }\end{array}$ & 13 & 20 & 20 & 21 & 24 & 3 \\
\hline $\begin{array}{l}\text { How quickly I will arrive at my } \\
\text { destination is the most important factor } \\
\text { in my transportation decisions }\end{array}$ & 12 & 27 & 28 & 17 & 14 & 1 \\
\hline $\begin{array}{l}\text { I would take public transportation if it } \\
\text { would get me to my destination more } \\
\text { quickly than a car }\end{array}$ & 14 & 29 & 20 & 20 & 13 & 3 \\
\hline $\begin{array}{l}\text { I would be willing to pay extra if it } \\
\text { would get me to my destination more } \\
\text { quickly }\end{array}$ & 13 & 28 & 31 & 17 & 9 & 2 \\
\hline $\begin{array}{l}\text { Comfort is the most important factor in } \\
\text { my transportation decisions }\end{array}$ & 15 & 33 & 29 & 16 & 5 & 0 \\
\hline $\begin{array}{l}\text { I would pay more for additional comfort } \\
\text { while traveling }\end{array}$ & 13 & 38 & 30 & 9 & 8 & 2 \\
\hline $\begin{array}{l}\text { I would be willing to accept a slower } \\
\text { speed in exchange for additional } \\
\text { comfort while traveling }\end{array}$ & 13 & 41 & 28 & 12 & 5 & 2 \\
\hline $\begin{array}{l}\text { I feel uncomfortable using public } \\
\text { transportation }\end{array}$ & 19 & 27 & 21 & 17 & 15 & 1 \\
\hline $\begin{array}{l}\text { Traveling by car is more enjoyable than } \\
\text { public transportation }\end{array}$ & 43 & 36 & 16 & 3 & 1 & 1 \\
\hline $\begin{array}{l}\text { I feel frustrated when I can't drive at the } \\
\text { speed limit or faster }\end{array}$ & 17 & 32 & 21 & 16 & 13 & 1 \\
\hline
\end{tabular}


Table 5 Results from mode choice model estimation

\begin{tabular}{|c|c|c|c|c|}
\hline \multirow[t]{2}{*}{ Parameter name } & \multicolumn{2}{|l|}{ Multinomial logit } & \multicolumn{2}{|c|}{ Mixed logit with panel effects } \\
\hline & Parameter estimate & $P$ value & Parameter estimate & $P$ value \\
\hline Alternative specific constant (bus) & 0.813 & 0.11 & 2.48 & $<0.005$ \\
\hline Alternative specific constant (completely driverless car) & 0.455 & 0.11 & 1.85 & $<0.005$ \\
\hline Alternative specific constant (normal car) & 0.852 & $<0.005$ & 2.24 & $<0.005$ \\
\hline Alternative specific constant (plane) & Fixed at zero & & Fixed at zero & \\
\hline Alternative specific constant (semi-driverless car) & -0.0640 & 0.86 & 1.31 & 0.01 \\
\hline Cost (dollars) & -0.00278 & $<0.005$ & -0.00600 & $<0.005$ \\
\hline Maximum travel speed (mph) & 0.0138 & $<0.005$ & 0.0130 & $<0.005$ \\
\hline Travel time (minutes), bus & -0.00127 & 0.11 & -0.00205 & 0.01 \\
\hline Travel time (minutes), completely driverless car & -0.00177 & $<0.005$ & -0.00225 & $<0.005$ \\
\hline Travel time (minutes), normal car & -0.00216 & $<0.005$ & -0.00268 & $<0.005$ \\
\hline Travel time (minutes), plane & -0.00375 & $<0.005$ & -0.00697 & $<0.005$ \\
\hline Travel time (minutes), semi-driverless car & -0.00141 & 0.07 & -0.00189 & 0.01 \\
\hline Panel effect & & & -3.42 & $<0.005$ \\
\hline Rho-squared (McFadden's) & 0.163 & & 0.267 & \\
\hline Adjusted rho-squared (McFadden's) & 0.160 & & 0.264 & \\
\hline
\end{tabular}

\subsection{Stated-preference results}

Table 5 contains results from the estimation of two specifications of mode choice models, using the data from the stated-preference survey.

Alternative specific constants and alternative specific travel time parameters were estimated, with generic parameters estimated for journey cost and maximum travel speed $[9,10]$. The multinomial logit results are included for completeness; the mixed logit with panel effects model is preferred as it accounts for the fact that stated-preference responses are not each independent from one another, because each respondent performed a set of ten scenarios. Taking this 'panel effect' into account improved goodness of fit (McFadden's rho-squared) and accounts for one dimension of bias in the parameter estimates, thereby yielding parameter estimates that are closer to the theoretical 'true' values.

All parameters for travel time and cost have the expected (negative) sign, indicating that, ceteris paribus, respondents were less likely to select alternatives that were more expensive or took additional time. These diagnostic results provide a measure of confidence that the data appear reasonable and suitable for subsequent analysis. To the authors' knowledge, the result that travelers appear to (positively) value the maximum speed at which they would travel in an automated car during their journey, independently from the duration of their journey, is a novel finding; it will have consequences for how automated cars are programmed to operate on both arterial streets [12] and freeways [13]. This apparent expression of consumer preference is somewhat in tension with, for instance, the suggestion by Anderson et al. [11, p. 30] that automated cars might 'enable lower peak speeds (improving fuel economy) but higher effective speeds (improving travel time).'

A counterintuitive result from the mode choice analysis is that the parameter for travel time for the 'Semi-driverless car' option is smaller than for the 'Completely driverless car.' This is contrary to a priori expectations, as it has been theorized by researchers [13, 14] that travelers in fully automated cars may have lower values (disutilities) of travel time, as being disengaged from the driving task would allow the vehicle occupant to focus on other productive or leisurely activities. Further analysis into this issue is needed to identify whether the result reported here is anomalous, or indicative of a misunderstanding on the part of researchers regarding people's preferences for the various technologies of automated cars.

\section{Conclusions}

In this study, we present results from a moderate-sample survey of the public's priorities for automated cars and preferences for their specific attributes in the context of a stated-preference survey. The context of the stated-preference survey is long-distance travel (specifically to visit relatives), and a novel result is that travelers appear to value both their 'effective' or average speed and their maximum speed (i.e., their 'cruising speed' under free-flow conditions). Results regarding the public's priorities 
demonstrate that safety appears to clearly be a higher priority than congestion reduction, a finding which has consequences for the car-following distances that are programmed into the control algorithms of automated cars. Documenting this finding is important, as decisions must be made in the near future by driving-algorithm designers, public-sector regulators, and ultimately the judiciary regarding the guidelines for acceptable automated drivingbehavior instructions.

Acknowledgements The authors wish to thank the anonymous referees for helpful feedback on earlier drafts. An earlier version of this study was presented at the 2017 Transportation Research Board conference (Poster \#17-3648); the authors thank attendees for helpful questions/feedback. Lustgarten thanks SUNY New Paltz's SURE program for financial support, and Le Vine acknowledges support of the University Transportation Research Center, Region 2 (Grant \# 49997-53-25, titled: Empirical Aspects of Autonomous Cars). The usual disclaimer applies: any errors in this paper are the authors' sole responsibility.

Open Access This article is distributed under the terms of the Creative Commons Attribution 4.0 International License (http:// creativecommons.org/licenses/by/4.0/), which permits unrestricted use, distribution, and reproduction in any medium, provided you give appropriate credit to the original author(s) and the source, provide a link to the Creative Commons license, and indicate if changes were made.

\section{References}

1. Schoettle B, Sivak M (2014) Public opinion about self-driving vehicles in China, India, Japan, the U.S., the U.K., and Australia. http://deepblue.lib.umich.edu/bitstream/handle/2027.42/109433/ 103139.pdf

2. Piao J, McDonald M, Hounsell N, Graindorge M, Graindorge T, Malhene N (2016) Public views towards implementation of automated vehicles in urban areas. Transport Research Procedia, vol. 14. http://www.sciencedirect.com/science/article/pii/ S2352146516302356
3. J. D. Power Inc. (2016) U.S. tech choice study. http://www. jdpower.com/resource/us-tech-choice-study

4. Zmud J, Sener IN, Wagner J (2016) Revolutionizing our roadways: consumer acceptance and travel behavior impacts of automated vehicles. Texas Transportation Institute. http:// d2dt15nnlpfr0r.cloudfront.net/tti.tamu.edu/documents/TTI-20168.pdf

5. Weinstein D (2016) Forecasting consumer adoption of autonomous vehicles and the impact on total vehicle sales. In: Paper presented at 5th annual automated vehicles symposium, July 19th-21st 2016, San Francisco

6. Kreuger R, Rashidi T, Rose J (2016) Adoption of shared autonomous vehicles: hybrid choice modeling approach based on stated-choice survey. In: Paper presented at the 95th annual meeting of the transportation research board, January 2016, Washington DC

7. NHTSA (2013) U.S. department of transportation releases policy on automated vehicle development. http://www.nhtsa.gov/ About+NHTSA/Press +Releases/U.S.+Department + of + Transportation + Releases + Policy + on + Automated + Vehicle + Development

8. Rose JM, Bliemer MCJ (2009) Constructing efficient stated choice experimental designs. Transp Rev 29(5):587-617

9. Ben-Akiva M, Lerman S (1985) Discrete choice analysis. MIT Press, Cambridge

10. Louviere JJ, Hensher DA, Swait JD (2000) Stated choice methods: analysis and application. Cambridge University Press, Cambridge

11. Anderson JM, Nidhi K, Stanley KD, Sorensen P, Samaras C, Oluwatola OA (2016) Autonomous vehicle technology: a guide for policymakers. Santa Monica, CA: RAND Corporation. http:// www.rand.org/pubs/research_reports/RR443-2.html

12. Le Vine S, Liu X, Zheng F, Polak J (2016) Automated cars: queue discharge at signalized intersections with 'Assured-ClearDistance-Ahead' driving strategies. Transp Res Part C Emerg Technol 62:35-54

13. Le Vine S, Kong Y, Liu X, Polak J (2016) Vehicle automation, legal standards of care, and freeway capacity. http://dx.doi.org/ 10.1007/s11116-017-9825-8

14. Malokin A, Mokhtarian PL, Circella G (2015) How do activities conducted while commuting influence mode choice? Testing public transportation advantage and autonomous vehicle scenarios. In: 94th annual meeting of the transportation research board, January 2016, Washington, DC 